\title{
Clinical Characteristics and Treatment Outcomes of Primary Malignant Melanoma of Esophagus: A Single Center Experience Running head: Outcomes of primary esophageal melanoma
}

\author{
Tae-Se Kim \\ Samsung Medical Center, Sungkyunkwan University School of Medicine \\ Byung-Hoon Min \\ Samsung Medical Center, Sungkyunkwan University School of Medicine \\ Yang Won Min \\ Samsung Medical Center, Sungkyunkwan University School of Medicine \\ Hyuk Lee \\ Samsung Medical Center, Sungkyunkwan University School of Medicine

\section{Poong-Lyul Rhee} \\ Samsung Medical Center, Sungkyunkwan University School of Medicine \\ Jae J. Kim \\ Samsung Medical Center, Sungkyunkwan University School of Medicine \\ Jun Haeng Lee ( $\nabla$ stomachlee@gmail.com ) \\ Samsung Medical Center, Sungkyunkwan University School of Medicine
}

\section{Research Article}

Keywords: Disease Attributes, Melanoma, Treatment Outcome, Survival

Posted Date: November 15th, 2021

DOI: https://doi.org/10.21203/rs.3.rs-1046902/v1

License: @ (i) This work is licensed under a Creative Commons Attribution 4.0 International License. Read Full License 


\section{Abstract}

Background

Primary malignant melanoma of esophagus (PMME) is an extremely rare disease with poor prognosis. The aim of this study was to determine the clinical characteristics and treatment outcomes of patients with PMME.

Methods

We retrospectively reviewed 17 patients diagnosed with PMME in Samsung Medical Center between 2000 and 2020. Clinical characteristics and survival outcomes were analyzed.

Results

15 patients (88.2\%) were male and the most common presenting symptom was dysphagia $(9 / 17,52.9 \%)$. On endoscopy, tumors were mass-forming in 15 patients $(88.2 \%)$ and diffusely infiltrative in two patients (11.8\%). Lesions were melanotic in 13 patients $(76.5 \%)$ and amelanotic in four patients (23.5\%). The most common anatomic location of tumor was lower esophagus (11/17, $64.7 \%)$. The disease was metastatic at the time of diagnosis in four patients (23.5\%). As for treatment, 10 patients (58.8\%) underwent surgery. In all 17 patients, the median overall survival was 10 months. In surgically treated patients, all patients experienced recurrence and the median disease-free survival was 4 months. There was no statistical difference in overall survival between patients with or without surgery. Patients with diffusely infiltrative tumor morphology had better overall survival compared to those with mass-forming tumor morphology $(P=0.048)$. Two patients who received immunotherapy as the first-line treatment without surgery showed overall survival of 34 and 18 months, respectively.

Conclusions

As radical resection for patients with PMME does not guarantee favorable treatment outcomes, novel treatment strategy is required. Further large-scale studies are warranted to determine the efficacy of immunotherapy for patients with PMME.

\section{Background}

Primary malignant melanoma of esophagus (PMME) is an exceedingly rare disease entity which is estimated to comprise only $0.1-0.2 \%$ of all esophageal malignancies [1]. PMME is known to behave aggressively and the estimated median overall survival is reported to be 10 to 12 months [2, 3], irrespective of treatment modalities. The mainstay of treatment for PMME has been esophagectomy because previous studies with limited number of cases suggested extended survival after radical resection [4-7]. However, due to the extreme rarity of the disease, its clinical features are sparsely reported and treatment strategies are not standardized. Recently, treatment with immune-checkpoint inhibitor such as Pembrolizumab or Nivolumab for metastatic PMME have shown promising results [8-10]. However, as the number of cases were limited, more studies with consistent results are required to validate the efficacy of such treatments.

In the present study, we reviewed the clinical and endoscopic features of 17 patients diagnosed with PMME in our institution and investigated their surgical and non-surgical outcomes.

\section{Methods}

\section{Research design and study population}

We retrospectively reviewed patients who were diagnosed with PMME between January 2000 and December 2020 at Samsung Medical Center. Only the patients with histologic confirmation of malignant melanoma in either biopsy or surgical specimen of esophagus were included. Patients with concurrent or a history of melanoma in other sites (including skin) were excluded. The study protocol was approved by the Institutional Review Board (IRB) of Samsung Medical Center (approval number: 2021-09-030-001) and conducted in accordance with the guidelines of the Declaration of Helsinki. Because of the retrospective nature of the study, written patient consent was waived by the IRB.

\section{Variables, data sources, and measurements}

Clinicopathological data were extracted from the intranet database of Samsung Medical Center. Two board-certified gastroenterologists (T.S.K. and B.H.M.) thoroughly reviewed the medical records and endoscopic findings. The gross findings were categorized into two patterns: mass-forming and diffusely infiltrative. Anatomical location was defined as upper (20-25 cm from the incisor teeth (IT)), middle (IT 25-30 cm), and lower (IT > $30 \mathrm{~cm}$ ) esophagus [11]. Because there is no standardized method of tumor staging for PMME, we categorized the patients into three staging categories with regard to lymph node metastases (LNM) and distant metastases status: localized disease (no LNM, N0), node positive disease (positive LNM, N+), and metastatic disease (M1) (adopted from Weiner et al. [3]). Surgical techniques were the same as those for patients with esophageal squamous cell carcinoma. Detailed description of surgical techniques used in our institution is reported elsewhere [12]. The survival time was calculated from the date of PMME diagnosis to the date of death or to the last date of follow-up (reference date: July 31, 2021). In patients who were lost to follow-up, survival data were retrieved from the National Health Insurance System Database. The disease-free survival time for patients who underwent surgery was calculated from the date of surgery for PMME to the date of first recurrence noticed during routine surveillance by computed tomography or esophagogastroduodenoscopy. Chemotherapy responses were measured according to the Response Evaluation Criteria for Solid Tumors (RECIST) version 1.1 [13]. 


\section{Statistical analysis}

Baseline clinicopathologic characteristics were summarized in mean \pm standard deviation or frequency (percent). The Kaplan-Meier survival curve was plotted for the whole study population and the differences between patient groups were tested using a log-rank test. Statistical significance was set at $\mathrm{P}<0.05$. All analyses were performed using SPSS version 25.0 (IBM SPSS Statistics for Windows, Version 25.0. Armonk, NY: IBM Corp.)

\section{Results}

\section{Clinical characteristics of the patients}

The clinical characteristics of 17 patients with PMME are summarized in Table 1. The median age was 60 years (range: 41-83) and 88.2\% (15/17) were male. The most common presenting symptom was dysphagia (52.9\%, 9/17). Endoscopically, 15 cases (88.2\%) presented with a mass-forming lesion, and 2 cases (11.8\%) were diffusely infiltrative. 13 cases (76.5\%) had dark pigmentation on endoscopic examination (Figure 1A) and four cases (23.5\%) did not (Figure 1B). In the majority $(64.7 \%, 11 / 17)$ of cases, tumors were located at the lower esophagus. Clinical staging was as follows: localized disease (8/17, $47.1 \%)$, node positive disease $(5 / 17,29.4 \%)$, and metastatic disease $(4 / 17,23.5 \%)$. 
Table 1

Baseline characteristics of patients with primary malignant melanoma of esophagus

\begin{tabular}{|c|c|}
\hline & $\begin{array}{l}\text { Total } \\
(n=17)\end{array}$ \\
\hline \multicolumn{2}{|l|}{ Age (years) } \\
\hline Mean \pm SD & $61.0 \pm 12.3$ \\
\hline Median (range) & $60(41-83)$ \\
\hline \multicolumn{2}{|l|}{$\operatorname{Sex}(\%)$} \\
\hline Male & 15 (88.2) \\
\hline Female & $2(11.8)$ \\
\hline \multicolumn{2}{|l|}{ Chief complaint (\%) } \\
\hline Dysphagia & $9(52.9)$ \\
\hline Epigastric discomfort & $2(11.8)$ \\
\hline Chest pain & $1(5.9)$ \\
\hline Dyspepsia & $1(5.9)$ \\
\hline Nausea & $1(5.9)$ \\
\hline Weight loss & $1(5.9)$ \\
\hline No symptom & $2(11.8)$ \\
\hline \multicolumn{2}{|l|}{ Smoking (\%) } \\
\hline No & $9(52.9)$ \\
\hline Yes & $8(47.1)$ \\
\hline \multicolumn{2}{|l|}{ Alcohol ingestion (\%) } \\
\hline No & $6(35.3 \%)$ \\
\hline Yes & $11(64.7 \%)$ \\
\hline \multicolumn{2}{|l|}{$\operatorname{BMI}\left(\mathrm{kg} / \mathrm{m}^{2}\right)$} \\
\hline Mean \pm SD & $23.8 \pm 2.6$ \\
\hline Median (range) & $23.7(19-30)$ \\
\hline \multicolumn{2}{|c|}{ Endoscopic morphology (\%) } \\
\hline Mass-forming & 15 (88.2) \\
\hline Diffusely infiltrative & $2(11.8)$ \\
\hline \multicolumn{2}{|l|}{ Amelanotic type (\%) } \\
\hline No & $13(76.5)$ \\
\hline Yes & $4(23.5)$ \\
\hline \multicolumn{2}{|l|}{ Endoscopic size $(\mathrm{cm})$} \\
\hline Mean \pm SD & $4.8 \pm 2.2$ \\
\hline Median (range) & $5.0(2-10)$ \\
\hline \multicolumn{2}{|l|}{ Endoscopic location (\%) } \\
\hline Upper & $3(17.6)$ \\
\hline Middle & $3(17.6)$ \\
\hline Lower & $11(64.7)$ \\
\hline Clinical staging (\%) & \\
\hline
\end{tabular}

* Two patients with diffusely infiltrative type tumor were excluded.

$\mathrm{SD}$, standard deviation; BMI, body mass index;

Page $4 / 10$ 


\begin{tabular}{|lc|}
\hline & $\begin{array}{l}\text { Total } \\
(\mathbf{n}=17)\end{array}$ \\
\hline Localized (N0) & $8(47.1)$ \\
\hline Node positive (N+) & $5(29.4)$ \\
\hline Metastatic (M1) & $4(23.5)$ \\
\hline Surgery (\%) & $5(29.4)$ \\
\hline No & $10(58.8)$ \\
\hline Yes & $2(11.8)$ \\
\hline Follow-up loss & \\
\hline * Two patients with diffusely infiltrative type tumor were excluded. \\
\hline SD, standard deviation; BMl, body mass index; \\
\hline
\end{tabular}

\section{Treatments and outcomes}

Among the 17 patients, 10 (58.8\%) received surgery, five (29.4\%) received chemotherapy or palliative care, and two (11.8\%) were lost to follow-up without treatment.

The outcomes of 10 patients who underwent surgical treatment are summarized in Table 2. The majority (70\%) of patients received Ivor-Lewis operation. In the surgical specimen, the mean tumor size was $5.4 \pm 2.8 \mathrm{~cm}$. The invasion depth was limited to submucosal layer in seven cases (70\%) while the muscularis propria was invaded in three cases (30\%). Resection margin was negative in all patients and LNM was identified in six patients (60\%). Post-operative complications were noticed in two patients (20\%). One patient had post-operative chylothorax and was successfully treated with thoracic duct ligation surgery. The other patient had transient vocal cord hypomobility which gradually improved in 3 months with rehabilitative training. Two patients who survived longer than three years (patient number 1 and 2 in Table 2) did not have LNM. With regard to adjuvant therapy, three patients received intravenous interferon-alpha (IFN-a) and two patients received adjuvant Pembrolizumab. Patients who received adjuvant IFN-a or adjuvant Pembrolizumab remained disease-free for 4, 4, and 1 months and 4 and 3 months, respectively. Apart from one patient lost during follow-up (patient number four in Table 2), recurrence was noticed in all patients who received surgery. Anastomosis (33\%) and peritoneum (33\%) were the most common sites of recurrence. The Kaplan-Meier estimate of median recurrence-free survival of surgically treated patients was only 4 months.

Table 2

Surgical outcomes for patients with primary malignant melanoma of esophagus

\begin{tabular}{|c|c|c|c|c|c|c|c|c|c|c|c|c|}
\hline No. & Age & Sex & $\begin{array}{l}\text { Surgery } \\
\text { type }\end{array}$ & $\begin{array}{l}\text { Tumor } \\
\text { location }\end{array}$ & $\begin{array}{l}\text { Tumor size } \\
\text { (pathology, } \\
\mathrm{cm} \text { ) }\end{array}$ & $\begin{array}{l}\text { Tumor } \\
\text { depth } \\
\text { (pathology) }\end{array}$ & LNM & $\begin{array}{l}\text { Resection } \\
\text { margin }\end{array}$ & $\begin{array}{l}\text { Adjuvant } \\
\text { therapy }\end{array}$ & $\begin{array}{l}\text { Disease- } \\
\text { free } \\
\text { survival } \\
\text { (months) }\end{array}$ & $\begin{array}{l}\text { Recurrent } \\
\text { organ }\end{array}$ & $\begin{array}{l}\text { Overall } \\
\text { survival } \\
\text { (months) }\end{array}$ \\
\hline 1 & 48 & M & 3-field & Upper & 0.8 & SM & $0 / 13$ & Negative & No & 36 & Anastomosis & 59 \\
\hline 2 & 53 & $\mathrm{~F}$ & $\mathrm{H}-\mathrm{L}$ & Middle & 7.5 & SM & $0 / 33$ & Negative & No & 15 & Femur, lung & 38 \\
\hline 3 & 70 & $M$ & $\mathrm{I}-\mathrm{L}$ & Lower & 8.5 & PM & $2 / 46$ & Negative & Pembrolizumab & 4 & Peritoneum & 25 \\
\hline 4 & 41 & $\mathrm{~F}$ & I-L & Lower & 2.2 & SM & $3 / 21$ & Negative & $\mathrm{N} / \mathrm{A}$ & N/A & N/A & 22 \\
\hline 5 & 65 & M & TG & EGJ & 4.0 & SM & $9 / 40$ & Negative & IFN-a & 4 & $\begin{array}{l}\text { Anastomosis, } \\
\text { liver }\end{array}$ & 11 \\
\hline 6 & 51 & $M$ & I-L & Lower & 6.0 & PM & $4 / 17$ & Negative & Pembrolizumab & 3 & $\begin{array}{l}\text { LN, peritoneum, } \\
\text { abdominal wall }\end{array}$ & 9 \\
\hline 7 & 77 & M & $\mathrm{H}-\mathrm{L}$ & Lower & 9.0 & PM & $9 / 25$ & Negative & No & 5 & $\begin{array}{l}\text { Anastomosis, } \\
\text { liver, } \\
\text { peritoneum }\end{array}$ & 8 \\
\hline 8 & 69 & M & I-L & Lower & 3.5 & SM & $0 / 7$ & Negative & IFN-a & 4 & Neo-esophagus & 7 \\
\hline 9 & 57 & M & 3-field & Middle & 4.5 & SM & $5 / 80$ & Negative & $\begin{array}{l}\text { RT followed by } \\
\text { IFN-a }\end{array}$ & 1 & $\begin{array}{l}\text { Supraclavicular } \\
\text { LN }\end{array}$ & 6 \\
\hline 10 & 53 & $M$ & $\mathrm{I}-\mathrm{L}$ & Lower & 3.5 & SM & $0 / 36$ & Negative & No & 4 & Brain & 6 \\
\hline
\end{tabular}

LNM, lymph node metastases; M, male; F, female; I-L, Ivor-Lewis operation; TG, total gastrectomy; EGJ, esophagogastric junction; SM, submucosa, PM, muscL propria; RT, radiotherapy; IFN-a, interferon-alpha; N/A, not available;

The outcomes of five patients who did not undergo surgery are summarized in Table 3. Two patients who received immunotherapy as the first-line treatment without surgery showed overall survival of 34 and 18 months, respectively. One of them had distant LN and adrenal gland metastases at presentation and received Nivolumab for 24 months ( $3 \mathrm{mg} / \mathrm{kg}$, biweekly) until disease progression. This patient is still currently alive and undergoing clinical trial. No 
immunotherapy related adverse effects were reported in either patients. Two patients who received conventional chemotherapy and/or radiotherapy as the first-line treatment survived 10 and 5 months, respectively. One patient who received supportive care only due to old age died 6 months after diagnosis.

Table 3

Outcomes of patients not undergoing surgery for primary malignant melanoma of esophagus

\begin{tabular}{|c|c|c|c|c|c|c|c|c|c|c|c|}
\hline No. & Age & Sex & Metastases & 1st treatment & $\begin{array}{l}\text { Time to } \\
\text { progression }\end{array}$ & $\begin{array}{l}\text { 2nd } \\
\text { treatment }\end{array}$ & $\begin{array}{l}\text { Time to } \\
\text { progression }\end{array}$ & 3rd treatment & $\begin{array}{l}\text { Time to } \\
\text { progression }\end{array}$ & $\begin{array}{l}\text { Overall } \\
\text { survival } \\
\text { (months) }\end{array}$ & Outcome \\
\hline 1 & 64 & $M$ & $\begin{array}{l}\text { LN, adrenal } \\
\text { gland }\end{array}$ & Nivolumab & 24 months & DPT & 2 months & $\begin{array}{l}\text { Trastuzumab } \\
\text { + Deruxtecan } \\
\text { (Clinical trial) }\end{array}$ & $\begin{array}{l}\text { Alive by } \\
2021.06 .30 .\end{array}$ & 34 & Alive \\
\hline 2 & 82 & M & None & Pembrolizumab & 2 months & DPT & 8 months & $\begin{array}{l}\text { Supportive } \\
\text { care }\end{array}$ & & 18 & Dead \\
\hline 3 & 63 & $M$ & $\begin{array}{l}\text { Lung, liver, } \\
\text { LN, adrenal } \\
\text { gland, } \\
\text { thyroid }\end{array}$ & DBPT & 2 months & IFN a & 2 months & $\begin{array}{l}\text { Supportive } \\
\text { care }\end{array}$ & & 10 & Dead \\
\hline 4 & 83 & M & None & Supportive care & & & & & & 6 & Dead \\
\hline 5 & 60 & M & Bone, LN & RT & 1 week & DPT & 2 months & Ipilimumab & 1 month & 5 & Dead \\
\hline
\end{tabular}

The Kaplan-Meier curve for overall survival in all 17 patients is shown in Figure 2A. The median survival was 10 months (95\% confidence interval (Cl): 6.0 14.0 months) and the estimated probability of one-year and three-year survival was $35.3 \%$ and $29.4 \%$, respectively. There was no statistical difference in overall survival between those who received surgery and those who did not (Figure 2B). There was no statistically significant difference in overall survival between patients with localized disease and node positive or metastatic disease (Figure 2C). Patients with diffusely infiltrative tumor morphology showed significantly better overall survival compared to patients with mass-forming tumor morphology (Figure 2D, $P=0.048$ ).

\section{Discussion}

Because PMME is a rare disease entity, its clinical features and treatment outcomes have not been fully defined. In the present single-center retrospective cohort study, we analyzed the clinical characteristics and survival outcomes of 17 PMME patients. We found that the majority of PMME patients are male, mainly complain of dysphagia and present with large dark pigmented mass at lower esophagus. Although surgery was performed in $58.8 \%$ of cases, no significant improvement of overall survival was found compared to those who underwent non-surgical treatments. Having a diffusely infiltrative tumor morphology was significantly associated with better overall survival than mass-forming tumor morphology. Two patients who received immunotherapy as the first-line treatment without surgery showed overall survival of 34 and 18 months, respectively.

PMME is notorious for its aggressive behavior. Sabanathan et al. [1] reported five-year survival of $4.2 \%$ after radical surgical resection in the review of 139 cases reported worldwide. In a previous study by Ahn et al. [2] which analyzed 19 South Korean PMME patients, the median overall survival was 12 months. In the present study, the estimated overall survival was 10 months ( $95 \% \mathrm{Cl}: 6.0-14.0$ months). Previous studies have shown conflicting results on the effect of surgery on survival outcome. While some studies have advocated surgery as a treatment of choice for either pallation or cure [1, 4-7, 14], relatively large-scale studies by Weiner et al. [3] $(n=56)$ and Cheung et al. [15] ( $n=39)$ failed to show significant association between surgery and prolonged overall survival. In the present study, whether or not the patient underwent surgery was not associated with overall survival (Figure 2B). We assume that this is because of the extremely aggressive biology of PMME. Even in clinically localized diseases, early systemic dissemination at microscopic level could occur in PMME patients. In fact, all surgically treated patients experienced recurrence in our study. Consistently, there was no survival difference between patients with clinically localized disease and patients with node positive or metastatic diseases (Figure 2C). Furthermore, esophagectomy is known for its high risk of post-operative morbidities [16] and diminished quality of life after surgery [17]. Given the aggressive behavior of PMME and equivocal efficacy of surgery as well as the aforementioned post-operative morbidity and quality of life issues, further large-scale studies are required to determine the value of surgery as the first-line treatment modality for patients with PMME.

Ahn et al. [2] previously reported that regarding gross tumor morphology, patients with flat pigmented pattern tumor showed significantly better overall survival compared to those with mass-forming pattern. Consistent results were found in our study (Figure 2D). In cutaneous melanoma, it has been suggested that superficial spreading and nodular subtypes are distinct entities having different molecular characterization [18]. We speculate that same explanation can be applied to mucosal melanoma such as PMME, but evidence is lacking. Interestingly, in a patient with diffusely infiltrative tumor morphology who underwent surgery (patient number 1 in Table 2), pathologic tumor size was only $0.8 \mathrm{~cm}$ and the rest of the pigmented infiltration was benign melanosis. Given that PMME usually presents with large mass, it is possible that the favorable outcomes of diffusely infiltrative type tumors could have been due to small tumor volume.

The diagnosis of PMME can be especially challenging when the tumor is amelanotic. Amelanotic PMME can be pathologically suggested when there is no melanin granule inside the tumor cells but when immunohistochemical (IHC) staining is positive for human melanin black 45 or S-100 and negative for cytokeratin [19]. The prevalence of amelanotic variant of PMME is estimated to be $10-25 \%$ [20]. In the present study, four cases (23.5\%) were amelanotic subtype. Clinicians should be aware that not all melanomas are dark pigmented and pathologic diagnosis may change from poorly differentiated carcinoma 
to malignant melanoma after IHC investigations. The prognostic value of amelanotic gross appearance is unclear. In this study, there was no significance difference of overall survival between melanotic and amelanotic subtypes.

Immunotherapy has been greatly successful in the treatment of cutaneous melanoma [21]. Although similar favorable results are anticipated for mucosal melanoma such as PMME, evidence is scarce due to its rarity. In the present study, we identified two patients who received adjuvant Pembrolizumab after surgery. Although statistical analysis was not feasible due to small number of cases, disease-free survival in patients who received adjuvant Pembrolizumab after surgery did not exceed the median disease-free survival of surgically treated patients not undergoing adjuvant immunotherapy (4 months). Notably, one patient with distant LN and adrenal gland metastases received 24 months of Nivolumab as first-line therapy and succeeded in long-term survival of 34 months (Table 3). As other recent case studies consistently report the effectiveness of immunotherapy for metastatic PMME [8, 10], further large scale studies are warranted to confirm the validity of immunotherapy for PMME.

There are evident limitations to this study. This was a retrospective study performed at a single tertiary referral center. As the number of cases was small, comprehensive comparative analyses were limited and conclusive statements could not be made.

\section{Conclusions}

PMME is a lethal disease with distinct clinical characteristics. Surgery did not significantly improve overall survival while patients with diffusely infiltrative tumor morphology showed better overall survival. As immunotherapy for PMME showed promising results even in patients with distant metastases, further large scale studies are warranted.

\section{Abbreviations}

PMME

Primary malignant melanoma of esophagus

IRB

Institutional review board

IT

Incisor teeth

LNM

Lymph node metastases

IFN-a

Interferon-alpha

Cl

Confidence interval

\section{Declarations}

\section{Ethics approval and consent to participate}

The study protocol was reviewed and approved by the Institutional Review Board of Samsung Medical Center (approval number: 2021-09-030-001). Because of the retrospective nature of the study, written patient consent was waived by the Institutional Review Board of Samsung Medical Center.

\section{Consent for publication}

Not applicable.

\section{Availability of data and materials}

The datasets used and/or analysed during the current study are available from the corresponding author on reasonable request.

\section{Competing interests}

The authors declare that they have no competing interests.

\section{Funding}

None declared.

\section{Author contributions}

The first two authors T.S.K. and B.H.M. contributed equally to this work. T.S.K., B.H.M.: conception and design; T.S.K., B.H.M.: analysis and interpretation of data; T.S.K., B.H.M., Y.W.M., H.L., P.L.R., J.J.K., and J.H.L.: acquisition of data; T.S.K., B.H.M.: drafting of the article; T.S.K., B.H.M., Y.W.M., H.L., P.L.R., J.J.K., and J.H.L.: critical revision of the article for important intellectual content. All authors read and approved the final manuscript.

\section{Acknowledgements}


The authors declare that they have no acknowledgements to make.

\section{References}

1. Sabanathan S, Eng J, Pradhan GN. Primary malignant melanoma of the esophagus. Am J Gastroenterol. 1989;84:1475-81.

2. Ahn JY, Hwang HS, Park YS, Kim HR, Jung HY, Kim JH, et al. Endoscopic and pathologic findings associated with clinical outcomes of melanoma in the upper gastrointestinal tract. Ann Surg Oncol. 2014;21:2532-9.

3. Weiner JP, Shao M, Schwartz D, Wong A, Schreiber D. Patterns of care and survival outcomes in the treatment of esophageal melanoma. Dis Esophagus. 2017;30:1-6.

4. Gupta V, Kochhar R, Sinha SK, Das A. Primary malignant melanoma of the esophagus: long-term survival after radical resection. J Thorac Oncol. 2009;4:1180-2.

5. Hamdy FC, Smith JH, Kennedy A, Thorpe JA. Long survival after excision of a primary malignant melanoma of the oesophagus. Thorax. 1991;46:397-8.

6. Harada K, Mine S, Yamada K, Shigaki H, Oya S, Baba H, et al. Long-term outcome of esophagectomy for primary malignant melanoma of the esophagus: a single-institute retrospective analysis. Dis Esophagus. 2016;29:314-9.

7. Wang S, Tachimori Y, Hokamura N, Igaki H, Kishino T, Kushima R. Diagnosis and surgical outcomes for primary malignant melanoma of the esophagus: a single-center experience. Ann Thorac Surg. 2013;96:1002-6.

8. Endo F, Akiyama Y, Onishi M, Fujisawa R, Sasaki N, Nikai H, et al. Primary esophageal malignant melanoma successfully treated with anti-PD-1 antibody for retroperitoneal recurrence after esophagectomy: A case report. Int J Surg Case Rep. 2020;75:152-6.

9. Ito S, Tachimori Y, Terado Y, Sakon R, Narita K, Goto M. Primary malignant melanoma of the esophagus successfully treated with nivolumab: a case report. J Med Case Rep. 2021;15:237.

10. Wang X, Kong Y, Chi Z, Sheng X, Cui C, Mao L, et al. Primary malignant melanoma of the esophagus: A retrospective analysis of clinical features, management, and survival of 76 patients. Thorac Cancer. 2019;10:950-6.

11. Berry MF. Esophageal cancer: staging system and guidelines for staging and treatment. J Thorac Dis. 2014;6 Suppl 3:S289-97.

12. Kim SH, Lee KS, Shim YM, Kim K, Yang PS, Kim TS. Esophageal resection: indications, techniques, and radiologic assessment. Radiographics. 2001;21:1119-37; discussion 38-40.

13. Eisenhauer EA, Therasse P, Bogaerts J, Schwartz LH, Sargent D, Ford R, et al. New response evaluation criteria in solid tumours: revised RECIST guideline (version 1.1). Eur J Cancer. 2009;45:228-47.

14. Hashimoto T, Makino T, Yamasaki M, Tanaka K, Miyazaki Y, Takahashi T, et al. Clinicopathological characteristics and survival of primary malignant melanoma of the esophagus. Oncol Lett. 2019;18:1872-80.

15. Cheung MC, Perez EA, Molina MA, Jin X, Gutierrez JC, Franceschi D, et al. Defining the role of surgery for primary gastrointestinal tract melanoma. J Gastrointest Surg. 2008;12:731-8.

16. Karl RC, Schreiber R, Boulware D, Baker S, Coppola D. Factors affecting morbidity, mortality, and survival in patients undergoing Ivor Lewis esophagogastrectomy. Ann Surg. 2000;231:635-43.

17. Jezerskyte E, Saadeh LM, Hagens ERC, Sprangers MAG, Noteboom L, van Laarhoven HWM, et al. Long-term health-related quality of life after McKeown and Ivor Lewis esophagectomy for esophageal carcinoma. Dis Esophagus. 2020;33.

18. Greenwald HS, Friedman EB, Osman I. Superficial spreading and nodular melanoma are distinct biological entities: a challenge to the linear progression model. Melanoma Res. 2012;22:1-8.

19. Kranzfelder M, Seidl S, Dobritz M, Brücher BL. Amelanotic esophageal malignant melanoma: case report and short review of the literature. Case Rep Gastroenterol. 2008;2:224-31.

20. Joob AW, Haines GK, 3rd, Kies MS, Shields TW. Primary malignant melanoma of the esophagus. Ann Thorac Surg. 1995;60:217-22.

21. Kaufman HL, Kirkwood JM, Hodi FS, Agarwala S, Amatruda T, Bines SD, et al. The Society for Immunotherapy of Cancer consensus statement on tumour immunotherapy for the treatment of cutaneous melanoma. Nat Rev Clin Oncol. 2013;10:588-98.

\section{Figures}



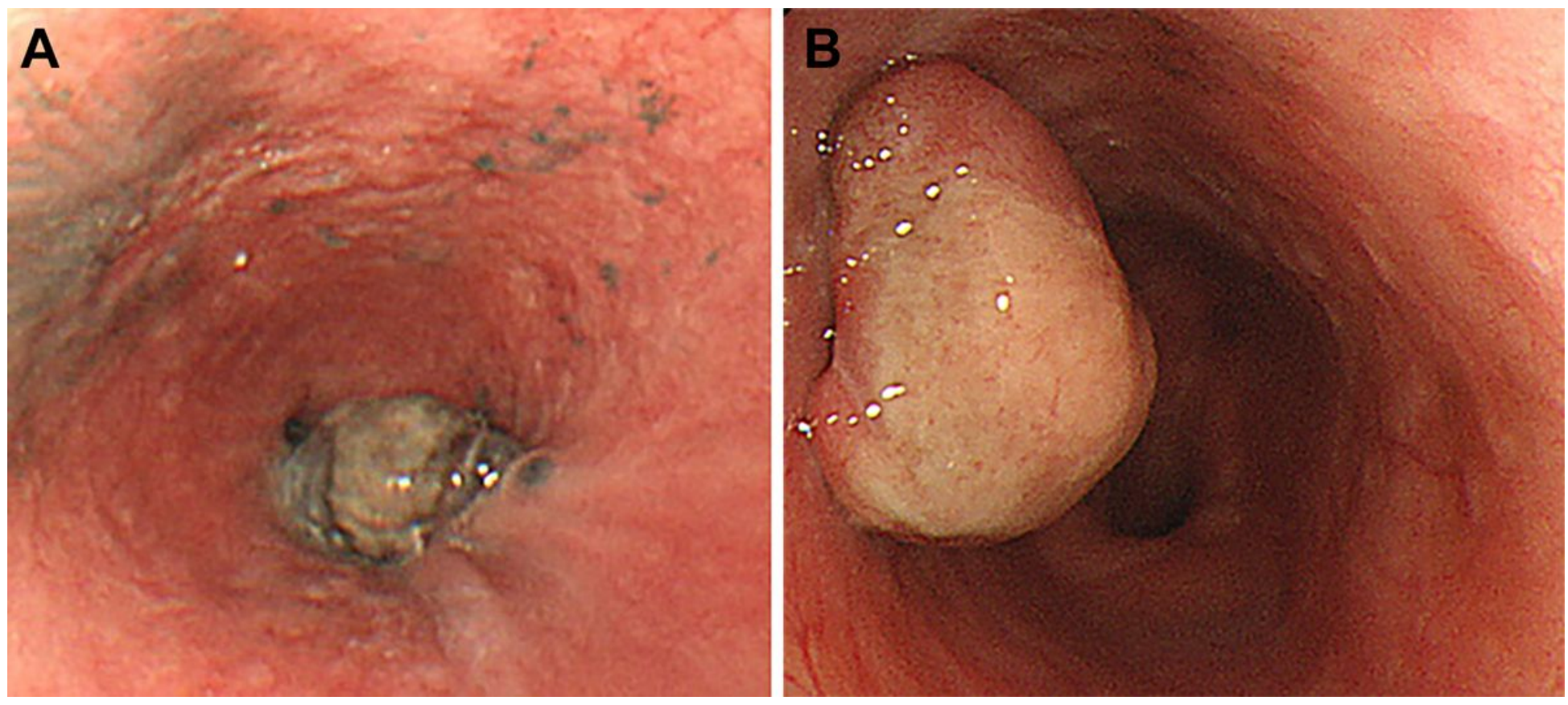

\section{Figure 1}

Representative images of melanotic and amelanotic type of primary malignant melanoma of esophagus. It typically presents as dark pigmented mass at lower esophagus (A). However, the absence of dark pigmentation in endoscopic examination does not exclude the possibility of malignant melanoma of esophagus (B).

A

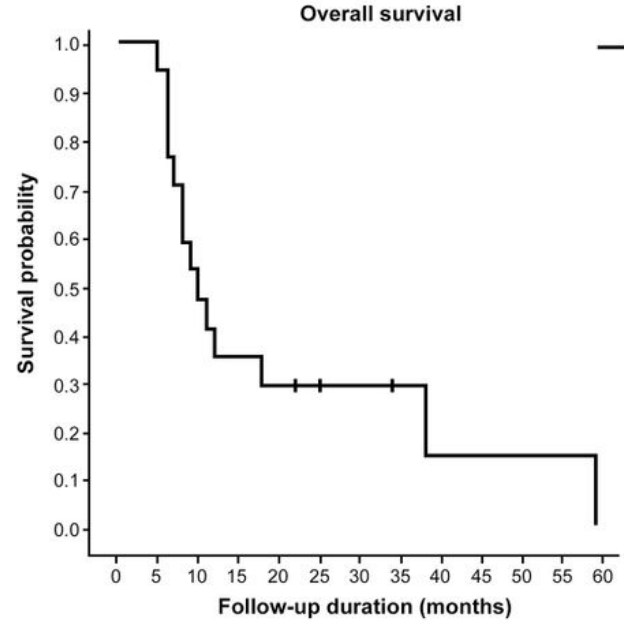

$\begin{array}{lllllllllllll}\text { Numbers at risk } & 17 & 17 & 9 & 6 & 5 & 4 & 3 & 2 & 1 & 1 & 1 & 1\end{array}$

C

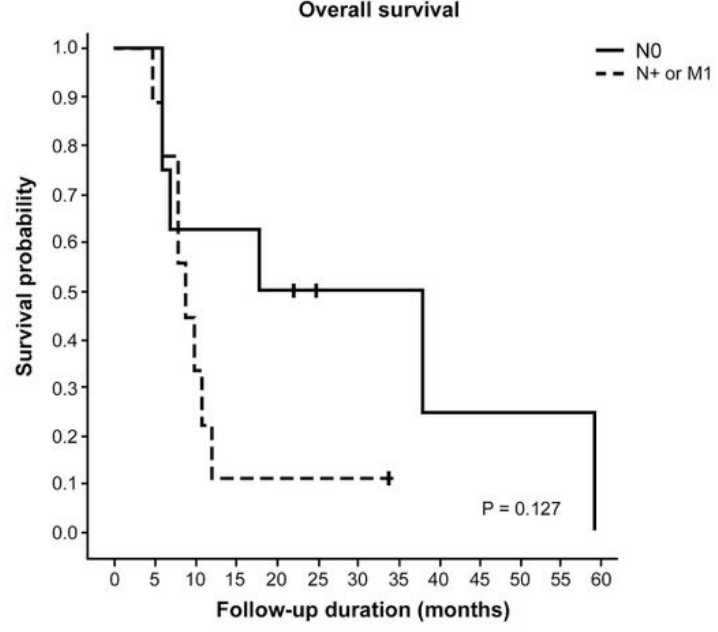

B Overall survival

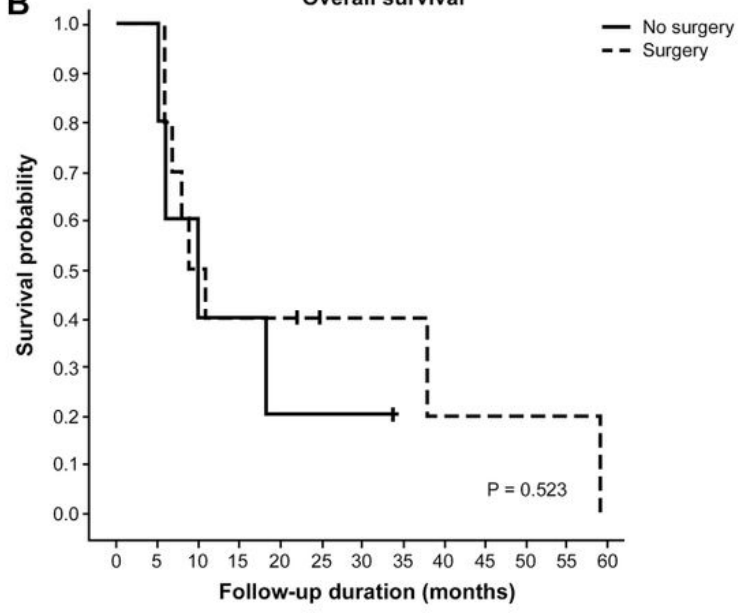

D

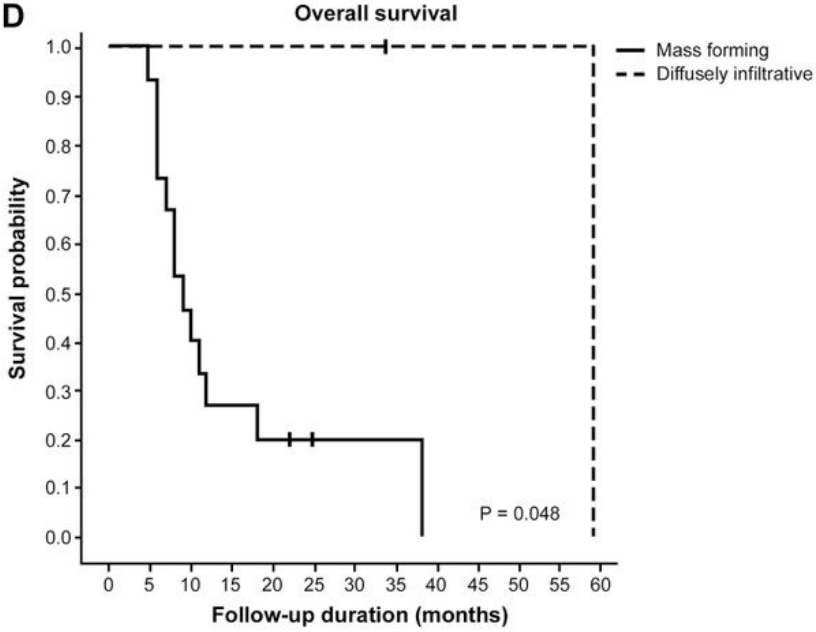


Kaplan-Meier overall survival curves in all patients (A) and according to treatment with or without surgery (B), stage groupings (C), and gross tumor morphology (D). 